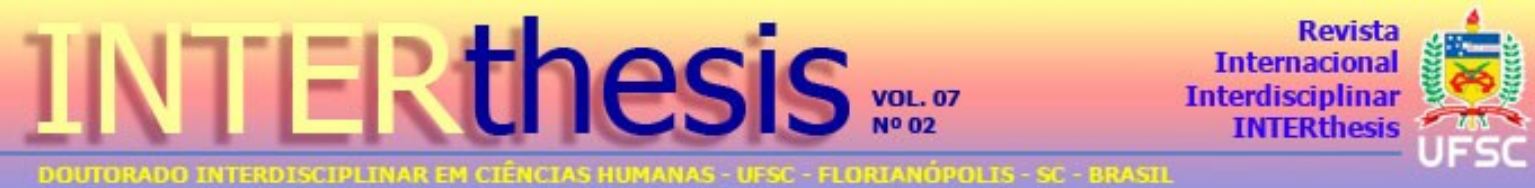

\section{COMPLEXIDADE E EPISTEMOLOGIA AMBIENTAL EM PROCESSOS SOCIOCULTURAIS GLOBAIS E LOCAIS}

\section{ENVIRONMENTAL COMPLEXITY AND EPISTEMOLOGY IN GLOBAL AND LOCAL SOCIO-CULTURAL PROCESSES}

\section{COMPLEJIDAD Y EPISTEMOLOGÍA AMBIENTAL EN PROCESOS SOCIOCULTURALES GLOBALES Y LOCALES}

\section{Dimas Floriani ${ }^{1}$}

\section{RESUMO:}

Partimos da idéia de 'modernidades múltiplas' em contraposição a um ethos central da modernidade ocidental capitalista, cuja racionalidade se produz no interior de um sistema enclausurado em si mesmo. Propomos que essas modernidades múltiplas se inscrevem no principio de emergência, marcado por diversas crises e por possibilidades de alternatividades.

Uma dessas crises aqui apontadas é de ordem representacional, na qual a idéia de 'ciencia' sofre uma crítica fundamental, tanto em suas bases epistemológicas, como nas práticas metodológicas de sua produção. O paradigma da complexidade atravessa diferentes campos da produção humana e social, em interação com os sistemas naturais, de onde emergem conflitos em nível da produção do próprio conhecimento (científico e não científico, em situação de potencial diálogo), da cultura globalizada mas igualmente localizada e de alternatividades nas formas de apropriação dos territórios e dos espaços de gestão política dos bens comuns.

Palavras-chave: complexidade ambiental. Imaginários sociais. Identidade e sociedade de rede. Bens comuns e cidadania.

\section{ABSTRACT: \\ We start with the idea of 'multiple modernities' as opposed to a central ethos of modern Western capitalist rationality which is produced within an enclosed system in itself. We propose that these multiple modernities enroll at the principle of emergency marked by several crises and possibilities of alternatives.

\footnotetext{
${ }^{1}$ Doutor em Sociologia (UCL- Louvain-la-Neuve, Bélgica). Professor Titular da Universidade Federal do Paraná (UFPR), Departamento de Ciências Sociais e Programa Interdisciplinar em Meio Ambiente e Desenvolvimento. E-mail: floriani@ufpr.br
} 
One such crisis pointed out here has a representational order in which the idea of 'science' undergoes a fundamental criticism, both in their epistemological, methodological practices and in their production. The paradigm of complexity goes across different fields of human production and social interaction in natural systems, where conflicts emerge at the level of production of knowledge itself (scientific and unscientific, in a situation of potential dialogue), the global culture but also located and of alternate forms of appropriation of territories and spaces of political management of the commons.

Keywords: Environmental complexity. Social imaginary. Identity and network society. The commons and citizenship.

\section{RESUMEN:}

Partimos de la idea de 'modernidades múltiples' en contraposición a un 'ethos' central de la modernidad occidental capitalista, cuya racionalidad se produce en el interior de un sistema en clausurado en si mismo. Proponemos que esas modernidades múltiples se inscriben en el principio de emergencia, marcado por diversas crisis y por posibilidades de alternativas. Una de esas crisis aquí señaladas es de orden representativo, en la cual la idea de 'ciencia' sufre una crítica fundamental, tanto en sus bases epistemológicas, como en las prácticas metodológicas de su producción. El paradigma de la complexidad atraviesa diferentes campos de la producción humana y social, en interacción con los sistemas naturales, de donde emergen conflictos en nivel de la producción del propio conocimiento (científico y no científico, en situación de potencial diálogo), de la cultura globalizada pero igualmente localizada y de alternativas en las formas de apropiación de los territorios y de los espacios de gestión política de los bienes comunes.

Palabras clave: complejidad ambiental. Imaginarios sociales. Identidad y sociedad de red. Bienes comunes y ciudadanía.

\section{COMPLEXIDADE E EMERGÊNCIAS COGNITIVAS NA MODERNIDADE}

A complexidade é um problema, um desafio e não uma resposta (MORIN, 2005, p. 559). O objeto deve vir unido ao sujeito e ao ambiente. No lugar de ser designado por sua exterioridade e independência em relação ao sujeito, o objeto deve ser entendido como sistema/organização.

Um paradigma da complexidade exige uma comunicação crescente e duradoura entre ciências sociais e exatas, entre reflexão filosófica e teoria científica. Segundo Morin, a definição de paradigma da complexidade deve compreender certos princípios de inteligibilidade articulados entre si e em que sejam abordados o físico, o biológico e o antropo-social. A idéia de complexidade deve vir associada com a compreensão de 
sentido do conhecimento científico nos seguintes pontos: a) ao progredir pela eliminação dos erros, o conhecimento científico não garante o aumento de verdades; b) nem o conhecimento científico, nem o espírito humano conseguem esgotar o sentido completo do real; c) eliminar a ignorância não é sinônimo de progresso científico; os progressos do conhecimento devem unir-se ao progresso da ignorância; d) são as regras do jogo entre verdade e erro que definem o que é verdade científica, uma vez que esta não está contida em suas teorias.

Esse paradigma exige uma reforma do pensamento, incorporando e reconhecendo as incertezas e as contradições. Deve ser uma ciência dos sistemas complexos auto-organizadores, ciência e evolução e ciência das condições de criação. Uma ciência capaz de corrigir desvios provocados por equívocos dos sistemas socioculturais que podem comprometer a continuidade da espécie humana e da própria vida planetária.

O enraizar-se da esfera antropo-social na esfera biológica e desta na matéria, não pode significar a redução de uma à outra. Trata-se de reconhecer os níveis de emergência. A ciência física não é puro reflexo do mundo físico, mas uma produção Cultural (MORIN, 1984, p. 315. A noção de complexidade libertou-se de seu sentido banal ao reunir em si o uno e o diverso, a ordem, desordem e organização. Deve aspirar a um saber não segmentado e não reducionista, reconhecendo que todo conhecimento é incompleto e inconcluso.

Historicamente, a modernidade na ciência foi representada por 4 princípios gerais: 1) o princípio da ordem. A idéia de ordem engloba a idéia de determinismo. Laplace via o mundo como uma máquina determinista perfeita e que representava o ideal de conhecimento; 2) o princípio da separação, bem formulado por Descartes: separa as matérias uma das outras e o objeto conhecido do sujeito conhecedor; 3) o princípio da redução: o conhecimento das unidades elementares permite conhecer os conjuntos dos quais elas são os componentes; 4) a validade da lógica dedutivoindutiva-identitária: abolir a contradição, colocando em seu lugar o valor de verdade quase absoluto à indução e um valor absoluto à dedução.

A humanidade, ademais de biológica é meta-biológica: ao nos tornarmos produto de uma evolução biológica, o sentido que atribuímos a essa evolução é dado pela 
evolução sociocultural. Uma nova concepção sistêmica sobre a história, o evento e a evolução, condicionará a emergência de formas alternativas de produção do conhecimento científico. Assim, não faz sentido opor uma evolução biológica a um 'fisicismo' estático, uma vez que a matéria também está enraizada no sistema e no evento. É com a evolução humana que emerge a história, ao incorporar na cultura eventos e experiências de diferentes ordens: técnicas, descobertas científicas, encontro de civilizações, conflitos e guerras.

Morin (2005, p.567) conclui: "hoje podemos dizer: somos filhos do cosmos, trazemos em nós o mundo físico, trazemos em nós o mundo biológico, mas com e em nossa singularidade própria. Em outros termos: para enfrentar o desafio da complexidade, necessitamos de princípios organizadores do conhecimento".

\section{ALGUNS REFERENCIAIS TEÓRICOS PARA ESTUDOS SOCIOAMBIENTAIS EM DIFERENTES ESCALAS ESPAÇO-TEMPORAIS}

\subsection{Para a constituição de uma epistemologia ambiental}

A epistemologia e as condições de produção e o acesso ao conhecimento científico e a outros tipos de conhecimento podem ser encontrados na Filosofia da Ciência, Sociologia e Antropologia da Ciência, na História da Ciência, na Ciência Cognitiva e na Etnociência ${ }^{2}$ que estão envolvidas neste debate. Contudo, não estamos especialmente interessados nos mecanismos cognitivos que tornam possível o ato de

\footnotetext{
2 "A invenção do nome Etnociência vem à publicidade em 1964 por William C. Sturtvant - curador do Instituto Norte-Americano Smithsonian de Etnologia; obviamente, os etnoconhecimentos, etnossaberes e as etnopráticas (re)conhecidos no campo (ou etnocampo) das etnociências pertence a todas as civilizações, sociedades e comunidades ancestrais e tradicionais dos multipovos da humanidade. Com o termo etnociência se designa a área de conhecimento multi, inter e transdisciplinar de documentação, estudo e valorização dos conhecimentos e das práticas produzidos por um grupo cultural e transmitidos por multimeios não convencionais. Conceituações outras de Etnociência são encontradas, tais como: etnografia de conhecimentos culturais, ciência dos conhecimentos culturais, movimento pedagógico multicultural e pluriétnico" (Carlos Fernandes - http://recantodasletras.uol.com.br/artigos/791494 acesso em 10 de agosto de 2009). Para estudos aplicados de etnociência no Brasil, consultar Berta G. Ribeiro (1987), Ubiratan D’Ambrosio (2001), Diegues (2000 ), Darrell Posey (1984 ) e na América Latina, dentre muitos outros Victor Toledo (2003) e Arturo Escobar (1997).
}

R. Inter. Interdisc. INTERthesis, Florianópolis, v.7, n.2, p.45-64, jul/dez. 2010 
conhecer (os sistemas neurofisiológicos e as tecnologias de inteligência), mas na relação que se estabelece entre este ato de conhecimento e os significados culturais que derivam dessa ação, no plano cognitivo do contexto social e histórico da atribuição de significados ao mundo, pelos sujeitos de conhecimento ${ }^{3}$.

A marcação do tempo pela cronologia evolutiva é uma representação dos sentidos humanos dos fenômenos da natureza e de sua auto-representação, como indivíduo, espécie, coletivo, cultura e sociedade. As rupturas são marcações importantes nos processos evolutivos naturais e sociais. A tomada de consciência humana desses processos ocorre de diferentes e múltiplas leituras representacionais do mundo: a religião, a mitologia, a literatura, a música, a arte, as oralidades, os discursos das ciências, da filosofia...

A marcação do tempo na produção discursiva da ciência, logo do forte debate cientificista (racionalidade popperiana, bachelardiana, neo-positivista ou mesmo kuhniana e feyerabendiana) é seguida pela desconstrução em torno a idéia de progresso, da técnica e da ciência (da escola de Frankfurt) e inaugurada faz mais de cem anos pelo nihilismo nietzscheano e pelo ceticismo weberiano.

No entanto, a novidade da reconstituição da função social da ciência recebe outro tratamento nos últimos 30 anos. Uma de suas teses é que há uma forte interação entre a cultura e os problemas produzidos pela evolução conceitual da ciência dentro da própria cultura (Prigogine, Wallerstein, Burke, Boaventura de Sousa Santos). Este ponto entra no debate sobre meio ambiente e desenvolvimento e abre-se para outras perguntas: O que faz mudar a base epistemológica do conhecimento científico? É a crítica social dirigida a favor ou contra a ciência e seus mecanismos lógicos e metodológicos, ou ainda, a simultaneidade ou heterogeneidade de ambos processos?

Para abordar essas questões, deve-se prestar atenção à fórmula lapidar weberiana sobre os conteúdos da ciência e de sua dimensão cultural: "O campo do

\footnotetext{
${ }^{3}$ A epistemologia ocidental é movida pelo objetivismo; o ato de conhecer é constitutivo do objeto de conhecimento em oposição às epistemologias não-ocidentais ou indígenas, para quem, "conhecer bem alguma coisa é ser capaz de atribuir o máximo de intencionalidade ao que se está conhecendo" (VIVEIROS DE CASTRO, 2002, p. 487). A noção de objeto, em oposição a sujeito constitui um longo e interminável capítulo da filosofia ocidental; na psicanálise, essa noção é inter-relacional no sentido intersubjetivo (mãe-filho), conforme discutido por Winnicott ( 1976).
} 
trabalho científico não se baseia nas conexões objetivas entre as coisas, mas nas conexões conceituais entre os problemas. Só quando é estudado um novo problema, com o apoio de um novo método, é que se descobrem verdades que inauguram novas e importantes perspectivas, emergindo daí uma nova ciência” ( WEBER, 1992, p.121).

Os debates sobre a aproximação de diferentes ciências interessadas em colaborar entre si, visando aprofundar e pesquisar temas transversais, na perspectiva multidisciplinar ou interdisciplinar, tais como saúde, tecnologia, ciências cognitivas e da inteligência, começam a esboçar-se nos anos 1960 com o debate sobre lógica e conhecimento científico e epistemologia das ciências, com a liderança de Jean Piaget (1967). Na América Latina, este debate epistemológico aplicado ao meio ambiente e à teoria da complexidade e interdisciplinaridade, assume importância no México, desde os anos 1980, com Rolando García (1994) e Enrique Leff (1994), na Colômbia com Angel Maya (1995, 2002), no Chile com Max-Neef (1991) e com Maturana e Varela (2007). No Brasil dos anos 1970, as abordagens da teoria ambiental eram quase de exclusividade da ecologia.

Os interesses sobre a questão socioambiental se limitavam ainda a alguns pesquisadores dispersos na ecologia e na geografia, além de algumas outras poucas disciplinas (antropologia, história, sociologia, economia, química...), nas quais as abordagens socioambientais eram pouco visíveis e relevantes do ponto de vista social e acadêmico-científico.

Os momentos de ruptura começam a se tornar evidentes nos anos de 1970 e 1980 quando alguns autores começam a questionar certas idéias hegemônicas de ciência, sua tradição positivista, e a crise que decorre de sua aplicação no domínio das sociedades, principalmente pelas tecnociências. Esses autores pertencem a diversas filiações do conhecimento científico e buscam 'novas alianças' entre as ciências da vida, da natureza e da sociedade (PRIGOGINE e STENGERS, 1980; SANTOS, 2002; MORIN, 1984; BATESON, 1978; CASTORIADIS, 1980; ATLAN, 1992; LEFF, 2009).

Esses diversos autores têm, uns mais, outros menos, participado do surgimento e da recente renovação das teorias da complexidade, herdeiras da cibernética, e correlatas aos desenvolvimentos da física dos sistemas dinâmicos (aqui incluídas as teorias do caos) e da assim chamada nova ciência, de orientação interdisciplinar, que 
restitui a importância das regularidades e do acaso na compreensão dos fenômenos e aproxima as novas física-química-biologia das "humanidades" (ATLAN, 2003).

Paralelamente a esse momento de "reconstituição" das teorias e das práticas científicas, implicando a instalação de profundos dissensos sobre o alcance e significado de ciência e sua função social, abre-se a perspectiva de outras alianças e contratos entre os saberes científicos, dando margem, inclusive, à revalorização dos saberes não-científicos, principalmente daqueles culturalmente arraigados.

Abrem-se, então, espaços de crítica institucional e de usos da ciência, possibilitando a introdução de alternativas de produção do conhecimento, tanto no interior das agências de conhecimento (universidades, laboratórios, agências fomentadoras de pesquisas) como dos movimentos sociais que questionam as formas e as aplicações do saber científico.

O dissenso ganha, dessa maneira, um espaço inédito especialmente no âmbito do meio ambiente e das alternativas do desenvolvimento sustentável. Embora esse movimento seja ainda minoritário e as práticas institucionais das agências de conhecimento sejam predominantemente disciplinares e segmentadas, pode-se dizer que a trajetória da constituição de outras identidades no campo acadêmico-científico e de suas articulações com o social já faz parte de uma realidade institucional.

Em síntese, a história social do conhecimento (científico e não-científico) traduz esse emaranhado de situações e de contextos. Neles se dão os confrontos entre concepções e sentidos de ciência, e entre os obstáculos institucionais assentados em conflitos culturais, na sua construção e ressignificações dos usos e aplicações sociais desses conhecimentos.

\subsection{Exigências para a construção de uma epistemologia socioambiental}

1) Uma epistemologia emergente deve tratar das condições de produção e de acesso ao conhecimento, não desvinculadas dos mecanismos de intervenção, do fazer saber e do saber fazer. 
2) Uma epistemologia socioambiental emergente deve saber integrar os fundamentos da uma filosofia do conhecimento, culturalmente condicionado e historicamente estabelecido, que leve em conta as trajetórias constitutivas de uma história da ciência, mas também dos saberes culturalmente enraizados e reinventados pela diversidade do pensamento vivo e corporificado em práticas, saberes críticos e tecnologias inventadas pela engenhosidade humana, em tenso diálogo,contraditório, criativo e crítico sobre os processos de interação entre as sociedades e a natureza.

3) Uma epistemologia socioambiental deve inscrever-se na confluência dos paradigmas em transição, refutando as simetrias unidimensionais de apenas uma matriz de pensamento e de valores; deve privilegiar o diálogo com a diferença, os espaços garantidos pelo pensamento complexo e híbrido e pela pluralidade diferenciadora. Mas também saber reconhecer as ingenuidades discursivas e a ideologização fácil, tanto afirmativas como negativas, simplificadoras e hegemonizantes.

4) Uma epistemologia socioambiental emergente é aquela que redefine a história do conhecimento, pela radicalidade das releituras dos processos de vida, pela natureza e o significado da vida, pela semântica e a polifonia dos sentidos culturais, em conjunção com a diversidade dos ecossistemas, fisicalidade do mundo e de sua permanente mutação e de sua permanente negação, integrando-se a uma nova filosofia dos processos culturais, cognitivos, tecnológicos, imaginativos, éticos, estéticos, utópicos, por meio de novas alianças afirmativas entre os tempos do espírito, da matéria e dos valores que cimentam a viabilidade da vida, das emoções, da alteridade, do ser acontecendo. Uma nova epistemologia desta ordem obriga a construir os sentidos da vida e do mundo pela educação (ou reeducação) dos sentidos.

5) Uma epistemologia socioambiental não pode operar sem uma teoria que englobe o entendimento da linguagem, do sujeito (Para Alain Badiou, "um sujeito é primeiramente aquilo que fixa um evento indecidível, porque 
assume o risco de decidi-lo"), do evento histórico-cultural, como um campo de disputas pela construção de sentidos práticos e simbólicos, o que implica interpretar o devir, o que acontece e o acontecido, nas interfaces sociedade-natureza.

\section{CULTURA, IDENTIDADES E SOCIEDADE EM REDE}

A emergência de novas racionalidades cognitivas e epistemológicas ocorrem em contextos fortemente marcados por assimetrias de poder na produção global da ciência, o que gera uma injustiça cognitiva global, apoiada na hierarquia entre ciência moderna e conhecimentos locais ou tradicionais, traduzindo a hierarquia entre o Norte e o Sul, entre desenvolvidos e subdesenvolvidos.

O cenário é, portanto, transnacional. Os espaços sociais já não devem ser reduzidos aos estados nacionais ou a instituições privadas, mas referidos a instâncias reguladoras internacionais, capazes de legislar sobre os grandes problemas globais, no domínio do risco e das catástrofes, sejam naturais ou sociais; e aqui se confundem as fronteiras entre o natural e o social. Por sua vez, e concomitantemente aos mecanismos de regulação, ocorre a emergência de estratégias sociais de resistência, em escala mundial, pela contestação de atores locais, reintroduzindo uma dimensão emancipatória, de alargamento do presente e encurtamento do futuro, conforme palavras de Boaventura de Sousa Santos $(2004 ; 2005)$.

Canclini, Bauman, Hall, Burke, Eagleton interpretam cultura e identidade na pósmodernidade globalizada ${ }^{4}$.

Canclini (1997) privilegia as dimensões culturais e comunicacionais, e também políticas da globalização. A internacionalização da cultura e da economia, e a transnacionalização de empresas e organismos intensificaram as dependências

\footnotetext{
${ }^{4}$ Estes autores foram resenhados na monografia de Daniela Sant'Ana, Práticas espirituais em uma comunidade budista de Curitiba: estratégias emancipatórias ou resistências ao desencantamento do mundo? Apresentada e aprovada no Curso de Ciências Sociais, da UFPR, 2009, sob a orientação do Prof. Dr. Dimas Floriani.
}

R. Inter. Interdisc. INTERthesis, Florianópolis, v.7, n.2, p.45-64, jul/dez. 2010 
recíprocas entre as nações. Novos fluxos comunicacionais informatizados geraram processos globais, com a flexibilização e eliminação de restrições e controles nacionais que limitavam as transações internacionais. Somando-se a isso, fluxos migratórios e turísticos favorecem a aquisição de línguas e imaginários culturais.

A dimensão cultural essencial da globalização é o papel das pessoas. Na época globalizada, além de nos relacionarmos efetivamente com muitas sociedades, podemos situar nossa fantasia em múltiplos cenários ao mesmo tempo. Assim desenvolvemos 'vidas imaginadas' e com a expansão global dos imaginários, incorporam-se ao nosso horizonte culturas dos outros, ou identidades, que, até há poucas décadas, sentíamos estranhas à nossa existência.

Os movimentos de globalização coexistem com a interculturalidade. O global se modula nas fronteiras, na multiculturalidade das cidades e na segmentação de públicos midiáticos. As cidades contemporâneas induzem a sociabilidade híbrida que nos leva a participar de forma intermitente de grupos cultos e populares, tradicionais e modernos, em meio a cruzamentos e intercâmbios. A globalização é o resultado de movimentos múltiplos e abertos, em parte contraditórios com vários modos possíveis de desenvolvimento, que implicam diversas conexões local-global e global-local.

O processo de hibridização, de que fala Peter Burke (2003), é o produto de encontros entre culturas distintas que marcam-se umas nas outras, independente das intenções dos indivíduos ou grupos, como conseqüência do processo de globalização e de migrações. A discussão de hibridização cultural tem como pano de fundo as interrelações possibilitadas pela globalização. Tendo como pressuposto que não cabe falar de culturas insuladas, as tradições culturais mantêm inevitavelmente contato com tradições alternativas.

Terry Eagleton (2005) também defende a idéia de que as culturas estão inevitavelmente envolvidas umas com as outras, que nenhuma é isolada ou pura já que são híbridas, heterogêneas e diferenciadas. O exemplo mais ilustrativo disso seria que nenhuma cultura humana é mais heterogênea e plural do que o modo de vida capitalista.

Bauman $(1998,1999,2001)$ e Hall (2005) propõem que o processo de globalização coloca novas características temporais e espaciais no mundo cultural. 
Enquanto na modernidade o tempo e o espaço eram um dos fatores de dinamismo, agora passam a resultar na diminuição de distâncias e de escalas temporais, o que acaba refletindo nas identidades culturais da atualidade. Os espaços se encontram mais híbridos, mesclados, ambivalentes, sem, contudo, perder antigas características. A globalização não é só de espaço e tempo, mas também de pessoas, de idéias e valores.

Por sua vez, Hall (2005) enfatiza os efeitos da globalização para as identidades culturais, através de transformação que vêm ocorrendo nas sociedades modernas desde o final do século $X X$, cujo efeito mais expressivo é a fragmentação das paisagens culturais de classe, gênero, sexualidade, etnia, raça e nacionalidade, que no passado nos forneciam sólidas localizações como indivíduos sociais.

Desde uma outra perspectiva, os estudos de Manuel Castells (1999, p.22-28) assinalam a importância da identidade dos atores sociais, enquanto processo de construção de significado, em base a um atributo cultural, ou ainda a um conjunto de atributos culturais interligados que prevalecem sobre outras formas de significado; por sua vez, o significado é definido como a identificação simbólica, por parte do ator social, da finalidade da ação praticada por ele. Na origem da construção de identidades estão os materiais oferecidos pela história, a geografia, biologia, instituições produtivas e reprodutivas, pela memória coletiva e por fantasias pessoais, pelos aparelhos de poder e revelações de caráter religioso.

Como as identidades são construídas socialmente em um contexto marcado por relações de poder, Castells propõe três formas e origens de construção de identidades: legitimadora, de resistência e de projeto.

Segundo o autor, em condições de modernidade tardia ou de sociedade em rede globalizada, as sociedades civis desarticulam-se ou se vêem reduzidas, por exemplo, os espaços públicos clássicos de organização institucionais (sindicalismo de classe, partidos políticos, etc.); em conseqüência, abrem-se outros espaços para a reconstrução de identidades defensivas baseadas em princípios comunais. Identidades locais se interligam com outras fontes de significados e reconhecimento social, seguindo um modelo altamente diversificado que dá margem a interpretações alternativas. 
Dessa maneira, quando o mundo se torna demasiadamente grande para ser controlado, os atores sociais passam a ter como objetivo transformá-lo no tamanho que Ihes possa concebê-lo a sua maneira. Quando as redes dissolvem o tempo e o espaço, as pessoas se agarram a espaços físicos, resgatando sua memória histórica. É possível que, desde essas comunas, novos sujeitos - atores coletivos de transformação social possam surgir, construindo novos significados em relação à identidade de projeto. As identidades de projeto parecem indicar uma crise estrutural da identidade legitimadora, que se produz no mesmo contexto de crise da sociedade civil e do Estado-Nação.

A ação ambiental que mais rapidamente se desenvolve nos últimos tempos, segundo Castells, é a mobilização das comunidades locais em defesa de seu espaço, contra a introdução de usos indesejáveis do meio ambiente. O controle sobre o espaço e o reforço da localidade é outro dos temas recorrentes entre diferentes componentes do movimento ambientalista.

O autor sugere ainda a idéia de uma oposição fundamental na sociedade de rede, entre duas lógicas espaciais: a do espaço de fluxos e do espaço de lugares. O espaço de fluxos organiza a simultaneidade de práticas sociais, por meio dos sistemas de informação e telecomunicações. O espaço de lugares privilegia a interação social e a organização institucional, cuja base é a contigüidade física. $O$ traço diferenciador da nova estrutura social, a sociedade em rede, é que a grande parte dos processos dominantes, concentrando poder, riqueza e informação, está articulada no espaço de lugares.

Contudo, a maior parte da experiência dos significados humanos se concentra ainda no espaço local. O localismo ambiental contesta a perda de relação entre essas diferentes funções ou interesses, submetidas ao princípio de uma representação mediada pela racionalidade técnica e abstrata exercida por interesses comerciais desenfreados e por tecnocracias sem qualquer compromisso ou responsabilidade. A lógica deste argumento pode ser traduzida pelo desejo de um governo de tamanho menor, que privilegie a comunidade local e a participação cidadã: a democracia de bases populares é o modelo político implícito na maioria dos movimentos ecológicos.

Em alternativas mais complexas, o controle sobre o espaço, a afirmação do local como fonte de significado e a preferência do governo local são elementos vinculados 
aos ideais de autogestão de inspiração anarquista, inclusive a produção em pequena escala e a auto-suficiência que conduz a uma crítica ao consumismo e a substituição do valor de troca do dinheiro pelo valor de uso da vida (CASTELLS, 1999, p. 155-6).

\section{DIÁLOGO DE SABERES E IMAGINÁRIOS SOCIAIS}

Em Imaginarios sociales y sustentabilidad, Enrique Leff (2010) questiona as vias de resolução de problemas que emergem da limitada capacidade de reflexão da modernidade sobre as condições de insustentabilidade que construiu desde 0 conhecimento perito adquirido, a eficácia do funcionamento do mercado para valorizar e conservar a natureza, a capacidade tecnológica para desmaterializar a produção, e inclusive a emergência de uma consciência ecológica planetária, para buscar uma solução à crise ambiental.

Autores envolvidos em pensar essa modernidade, tais como Beck ou Giddens, associam uma modernidade reflexiva a uma destruição criativa que não é mais representada pela revolução nem pela crise, mas pela vitória da modernização (ecológica) ocidental.

Diante da dificuldade de forjar uma nova "ciência da sustentabilidade" para restaurar as falhas da modernidade, Leff explicita a construção de uma racionalidade ambiental, assentada nos potenciais ecológicos e nos sentidos culturais da vida, na ética da outridade e em uma política da diferença. Com isso, a complexidade ambiental é entendida como a intervenção do mundo pelo conhecimento, por onde emerge uma complexidade ontológica e epistemológica, em um hibridismo entre o real e o simbólico, no encontro de um mundo super-economizado e super-tecnologizado com a resistência do ser e a reinvenção das identidades, na reapropriação social da natureza.

Por isso, a capacidade de resposta sobre a crise civilizatória de hoje exige outras fontes de pensamento e de ação, além da possível reflexão do conhecimento moderno sobre as bases da modernidade. Com o recurso da reflexividade para a irrupção de categorias impensadas, inspiradas em Bourdieu, Leff lança a pergunta sobre a 
possibilidade de interpretar e resgatar os imaginários pela hermenêutica de uma comunidade reflexiva que atuam na estruturação social como bases ontológicas da consciência prática.

Assim, de um lado ocorre a reflexividade comunitária em termos de uma autoreflexão das comunidades sobre seus imaginários; de outro, abre-se uma hermenêutica como método que interpreta os códigos e práticas culturais, estruturadores de tais imaginários sociais. Categorias originárias tais como o "vivir bien" ou "buen vivir", dos povos aimará, formas instituídas e rotinizadas de significação na produção de bens substantivos convertem-se em lugares de resistência e meios de emancipação frente ao mundo globalizado. É aqui onde entram em cena os imaginários sociais que se reatualizam nas lutas de resistência e de reinvenção de seus mundos de vida.

Essa modalidade de imaginários que denotam a autonomia de cada cultura, não se manifestam apenas nas formas de adaptação e de negociação política para suas autonomias, mas são expressão de um diálogo de saberes, enquanto resistências e adaptações ao conhecimento moderno, na perspectiva de uma política da diversidade e da diferença, nas alianças entre os imaginários da sustentabilidade dos povos indígenas e a racionalidade ambiental.

Para Leff, se a resposta à crise ambiental não pode esperar que ocorra desde uma consciência ecológica, é necessário localizá-la nos imaginários sociais para interpelar as formas de como se instauram as leis fundamentais da natureza e da cultura; isto porque os imaginários estão enraizados nas identidades que configuram o ser cultural. Formas do ser nos quais se desdobram formas de pensar e de sentir 0 mundo; práticas, hábitos e costumes que não refletem a verdade do real, que nem sempre se traduz em formas discursivas mas que criam mundos de vida. Contudo, quando esses imaginários se expressam lingüisticamente, assumem um aspecto coletivo e dialógico, isto é, uma força imaginativa cuja perspectiva se traduz em invenção de novos mundos de vida. 


\section{OS ESTUDOS SOBRE "BENS COMUNS" E CIDADANIA}

Para alguns autores (HELFRICH, 2008; BOLLIER, 2008), os bens comuns são as redes da vida que nos sustentam. São o ar, a água, as sementes, o espaço sideral, a diversidade de culturas e o genoma humano. São uma rede tecida para gerar os processos produtivos, reprodutivos e criativos. São ou nos proporcionam os meios para alimentar-nos, comunicar-nos, educar-nos e transportar-nos.

O patrimônio comum - seja natural, cultural ou social - está associado à riqueza e vitalidade das relações sociais, muitas vezes comunitárias. Um recurso de uso comum (common pool resource) é um bem econômico compartilhado, independente de qualquer sistema de direitos legais de propriedade.

Bens comuns (commons) se entende como conceito que dá sentido e orientação a uma proposta política e que nos situa em quatro temas essenciais: 1) o controle sobre o uso e manejo de recursos e bens que formam nosso patrimônio social, natural e cultural; 2) o acesso a tais recursos e bens; 3) o processo de produção e reprodução social tanto de bens como do bem comum; 4) a justiça distributiva na divisão dos benefícios que emergem de nosso acervo comum.

Os bens comuns supõem uma lógica muito diferente da do mercado para o manejo dos recursos. Oferecem formas de propriedade e administração mais eqüitativas que a propriedade privada. Buscam a sustentabilidade do recurso a longo prazo. No âmbito dos bens comuns se respeita o auto-governo como um princípio importante.

Contudo, os sistemas de manejo podem variar muito. Não existe um modelo universal. Diferentes sistemas são necessários devido à diferente natureza dos recursos, sua escala e a comunidade de que se trate. Por exemplo, comunidades de pesca pequenas podem outorgar direitos de pesca em certas águas e vigiar de maneira mais eficaz do que um governo federal que não garante esses mesmos direitos. Ao contrário, quando se trata do espaço elétrico usado pela rádio e televisão, é provável que se necessite do governo para que se estabeleça um sistema geral de regras técnicas e legais. Contudo, essas regras podem favorecer aos grandes grupos de rádio 
e televisão corporativos. Por sua vez, outros atores como os programadores de software livre podem operar de maneira totalmente independente de governo. Este tipo de "comunidades" se valem de regras formais e normas sociais para sua autoorganização.

Os bens comuns são os espaços, o tecido pela sociedade, os artefatos, os eventos e as técnicas culturais que são de uso e gozo comum, como o poço de um povo, o manejo de um espaço como praça pública urbana, uma receita, um idioma ou o saber coletivo compartilhado pela internet. Ao abordá-lo como uma 'coisa' se corre o risco de perder de vista que se trata de uma relação social e que não existe um common sem um sujeito social específico.

Segundo os citados autores, a discussão continuará a respeito de se nos serve ou não uma definição global-genérica para continuar desenvolvendo uma proposta paradigmática política no contexto da América Latina. Uma vez que engloba tanto o mundo real como o virtual, trata-se de uma proposta que sendo conceitual traz a diversidade, possuindo marcas de cada localidade e de cada realidade sócioeconômica.

\section{ALGUMAS CONSIDERAÇÕES FINAIS}

Partimos da idéia de "modernidades múltiplas", em oposição a uma modernidade fechada em si mesma, na qual se inscrevem diferentes emergências alternativas, como produção cognitiva dentro do marco de um pensamento complexo, o que implica um tratamento de ruptura em relação às epistemologias tradicionais, de cunho positivista e disciplinar, que separa a natureza das sociedades. Para superar as restrições mentais dos modelos epistemológicos hegemônicos, apresentamos algumas exigências para a construção de uma epistemologia socioambiental, em áreas de fronteira das ciências e dos conhecimentos não-científicos, de ordem cultural.

Por sua vez, elegemos alguns exemplos de emergências de caráter cognitivo, cultural e dos bens comuns, expressões de resistências e de alternatividades no 
processo de globalização, cujas inscrições promovem identidades de resistências e de projetos.

As identidades devem ser entendidas como processos de constituição e reconstituição de valores culturais presentes não apenas como fenômeno de consciência, mas também como uma manifestação da ação, da prática e ao mesmo tempo de sua incorporação nas instituições sociais.

Como bem apontou Leff, os valores não podem ser reduzidos a representações mentais ou a simples fenômenos de consciência. Desta maneira, é atribuído aos valores uma condição ontológica, sendo que os mesmos estão sempre em desenvolvimento e não são simplesmente dados.

Por seu lado, a exposição sobre os bens comuns e a cidadania, enquanto emergência ou alternatividade aos modelos dominantes de propriedade privada, a gestão comum dos territórios e dos recursos naturais, são algumas evidências de um alter ego que pensa o mundo nos limites da insustentabilidade, criando outras formas de atividade cidadã e de sustentabilidade. 


\section{REFERÊNCIAS}

ATLAN, H. Ruído e determinismo: diálogos espinosistas entre antropologia e biologia. Mana, v.9, n.1, p. 123-37, abril 2003.

BATESON, G. Steps to an ecology of mind. Londres: Paladin, 1978.

BAUMAN, Z. A Globalização: as conseqüências humanas. Rio de Janeiro: Jorge Zahar, 1999.

BAUMAN, Z. Identidade. Entrevista a Benedetto Vecchi. Rio de Janeiro: Jorge Zahar, 2005.

BOLLIER, David. Los bienes comunes: un sector soslayado de la creación de riqueza. Genes, bytes y emisiones: bienes comunes y ciudadanía (Silke Helfrich compiladora). Fundación Heirich Böll, 2008. Disponível em: http://creativecommons.org/ ; www.boell-latinoamerica.org.

BURKE, Peter. Uma História Social do Conhecimento. Rio de Janeiro: Jorge Zahar, 2003.

CASTELLS, Manoel. O Poder da Identidade. CASTELLS, Manoel. A era da informação: Economia, sociedade e cultura. v.2. São Paulo: Paz e Terra, 1999.

EAGLETON, T. A Idéia de Cultura. São Paulo: Editora Unesp, 2005.

FEYERABEND, P. Tratado contra el método. Madrid: Tecnos, 2003.

FLORIANI, D. Conhecimento, Meio Ambiente e Globalização. Curitiba: Juruá/PNUMA, 2004.

FLORIANI, D.; KNECHTEL, M.do R. Educação Ambiental: Epistemologia e Metodologias. Curitiba: Vicentina, 2003. 
GARCÍA, R. Interdisciplinariedad y sistemas complejos.In Ciencias Sociales y formación ambiental. Barcelona: Gedisa Editorial, 1994.

GARCÍA CANCLINI, N. La globalización Imaginada. México,Buenos Aires, Barcelona: Paidós, 1999.

HALL, S. A identidade cultural na Pós-Modernidade. Rio de Janeiro: DP\&A editora, 2005.

HELFRICH, Silke. Bienes Comune y ciudadanía: uma invitación a compartir. In: HELFRICH, Silke . Genes, bytes y emisiones: bienes comunes y ciudadanía, Introducción. Fundación Heirich Böll, 2008. Disponivel em: http://creativecommons.org/ ; www.boell-latinoamerica.org

HELFRICH, Silke. Commons: ámbitos o bienes comunes, procomún o "lo nuestro". Las complejidades de la traducción de un concepto. HELFRICH, Silke. Genes, bytes y emisiones: bienes comunes y ciudadanía. Fundación Heirich Böll, 2008. Disponivel em: http://creativecommons.org/ ; www.boell-latinoamerica.org

KUHN, T.S. A Estrutura das Revoluções Científicas. 5 ed. São Paulo: Editora Perspectiva, 2000.

LEFF, Enrique. Imaginários sociales y sustentabilidad. Cultura y representaciones sociales - um espacio para el diálogo transdisciplinario, v.5, n.9, set. 2010 Disponível em: http://www.culturasyrs.org.mx/

MATURANA, H.; VARELA, F. El árbol del conocimiento. Santiago de Chile: Editorial Universitaria, 2007.

MAYA, A. A. La fragilidad ambiental de la cultura. Bogotá: IDEA/Editorial Universidad Nacional, 1995.

MAYA, A. A. El retorno de Ícaro: la razón de la vida: muerte y vida de la filosofía: una propuesta ambiental. Bogotá: IDEA/PNUMA, 2002.

MAX-NEEF, M. Human scale development. New York: Apex, 1991.

R. Inter. Interdisc. INTERthesis, Florianópolis, v.7, n.2, p.45-64, jul/dez. 2010 
MORIN, E. Ciencia con Conciencia. Barcelona: Anthropos, 1984.

MORIN, E. Os desafios da complexidade. In A Religação dos Saberes. O desafio do século XXI (org. Edgar Morin), p.559-67. Rio de Janeiro: Bertrand Brasil, 5ª . Edição, 2005.

PIAGET, Jean. L'épistémologie et ses variétés. In : Encyclopédie de la Pléiade. Logique et connaissance scientifique. Paris: Gallimard, 1967.

POLANYI, M. The tacit dimension. Chicago: University of Chicago Press, 1967.

POPPER, K. Objective knowledge: an evolutionary approach. Oxford: Clarendon, 1972.

PRIGOGINE, I.; STENGERS, I. A nova aliança. Brasilia: Editora da UnB, 1980.

SOUSA SANTOS, B. de. Um discurso sobre as ciências. 3 ed. São Paulo: Cortez Editora, 2005.

SOUSA SANTOS, B de. Para uma sociologia das ausências e uma sociologia das emergências. In: SOUSA SANTOS, B. de (Org.) Conhecimento Prudente para uma Vida Decente. São Paulo: Cortez Editora, 2004.

WEBER, Max. A "objetividade" do Conhecimento na Ciência Social e na Ciência Política. Metodologia das Ciências Sociais, Parte 1. São Paulo: Cortez Editora/Editora da UNICAMP, 1992. p.107-154.

Dossiê:

Recebido em: 30/10/2010

Aceito em: $27 / 11 / 2010$ 